$200 \mathrm{eV}-10 \mathrm{keV}$ boron implantation and rapid thermal annealing: Secondary ion mass spectroscopy and transmission electron microscopy study

M. I. Current and D. LopesM. A. Foad and J. G. EnglandC. Jones and D. Su

Citation: Journal of Vacuum Science \& Technology B: Microelectronics and Nanometer Structures Processing, Measurement, and Phenomena 16, 327 (1998); doi: 10.1116/1.589805

View online: http://dx.doi.org/10.1116/1.589805

View Table of Contents: http://avs.scitation.org/toc/jvn/16/1

Published by the American Institute of Physics 


\title{
$200 \mathrm{eV}-10 \mathrm{keV}$ boron implantation and rapid thermal annealing: Secondary ion mass spectroscopy and transmission electron microscopy study
}

\author{
M. I. Current ${ }^{\mathrm{a})}$ and D. Lopes \\ Applied Materials, Santa Clara, California \\ M. A. Foad and J. G. England \\ Applied Materials, Horsham, West Sussex, England \\ C. Jones and D. Su \\ Philips Materials Analysis Group, Sunnyvale, California
}

(Received 6 April 1997; accepted 13 November 1997)

\begin{abstract}
Atomic profiles (secondary ion mass spectroscopy) and cross-section transmission electron microscopy (TEM) images of selectively etched, annealed profiles were studied for boron energies from $200 \mathrm{eV}$ to $10 \mathrm{keV}$ and rapid thermal processing anneals at 900,975 , and $1050{ }^{\circ} \mathrm{C}$. Consistent variations of dopant depth were obtained over this process range. TEM images showed evidence of lateral dopant variation near the edges of poly-Si gate structures, perhaps an effect of lateral straggling and reflection of ions from the polymask. (c) 1998 American Vacuum Society. [S0734-211X(98)06801-2]
\end{abstract}

\section{INTRODUCTION}

Production activities with $0.25 \mu \mathrm{m}$ devices $[256 \mathrm{Mb}$ DRAM (dynamic random access memory) and advanced microprocessors] have hardly begun and yet critical attention has already begun to focus on the processing needs for doping of devices that are 2-3 generations ahead. The increasingly lengthy, complex, and expensive path to a fully integrated process and advanced device design requires that we determine that there are no "show stoppers" well in advance of the process need. The 1994 Semiconductor Industry Association (SIA) Technology Roadmap ${ }^{1}$ identified the challenge of shallow junction $(<0.1 \mu \mathrm{m})$ formation to be a critical issue for fabrication of advanced devices. The challenge comes in at least five stages. At the first is the need to understand the behavior of dopants and defects under the conditions required for shallow junction formation. ${ }^{2}$ The second stage is the development of production-worthy tools that can function reliably and efficiently in the shallow junction process regime. The third stage is the work of integrating individual process steps, in this case ion implantation and rapid thermal processing (RTP), into a robust process unit. The following stages are the integration of the shallow junction doping process with contact and interconnect technology to create a complete process flow for devices with the desired feature size and density and finally the design and production of advanced, large-scale circuits to exploit this process capability. This work takes advantage of recent advances in the second state, development of new tools for ion implantation, ${ }^{3}$ and rapid thermal processing, ${ }^{4-6}$ to address the initial parts of the third stage of this process for $0.25-0.1 \mu \mathrm{m}$ devices. The task of estimation of the processing conditions for as yet to be developed advanced device technologies has been worked

${ }^{a)}$ Electronic mail: Current_Michael@amat.com by many people and with many approaches. ${ }^{7}$ One of the most obvious and, as it turns out, successful strategies is to take the lead from two famous "laws" that have described integrated circuit devices for several decades now, the exponential growth in time of the number of transistors (Gordon Moore's "law" ${ }^{8}$ ) and the exponential decrease in the cost per bit of memory circuits, ${ }^{9}$ and look for characteristics of advanced processes and devices which change in an exponential fashion with time. ${ }^{10}$ The process conditions in this study were chosen to span the energy range for boron im-

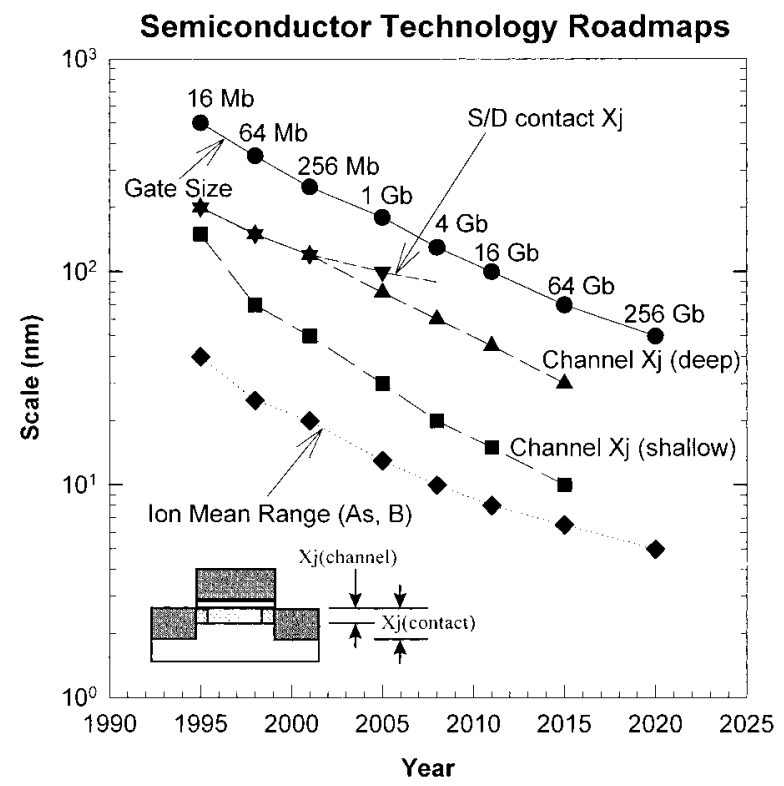

FIG. 1. Expectations for scaling of gate size, junction depths for source/drain contacts and channel doping (including source/drain extensions), and typical ion ranges for As and $\mathrm{B}$ dopant for CMOS technologies out to $256 \mathrm{~Gb}$ DRAMs (50 nm gates in $2020 \mathrm{AD}$ ) (Ref. 1). 
TABLE I. Source/drain (S/D) device and process conditions. (Note: The range in S/D junction depth and B implant energies corresponds to an estimate of the differences between S/D contact and extensions.)

\begin{tabular}{ccccc}
\hline \hline Device technology & Gate size & S/D junction & B energy & S/D anneal cycle \\
\hline $16 \mathrm{Mb}$ & $0.50 \mu \mathrm{m}$ & $0.15-0.20 \mu \mathrm{m}$ & $10-15 \mathrm{keV}$ & $\cong 1000^{\circ} \mathrm{C} / 30 \mathrm{~min}$ \\
$64 \mathrm{Mb}$ & $0.35 \mu \mathrm{m}$ & $0.10-0.18 \mu \mathrm{m}$ & $7-12 \mathrm{keV}$ & $\cong 1100^{\circ} \mathrm{C} / 30 \mathrm{~s}$ \\
$256 \mathrm{Mb}$ & $0.25 \mu \mathrm{m}$ & $50-120 \mathrm{~nm}$ & $5-10 \mathrm{keV}$ & $\cong 1050^{\circ} \mathrm{C} / 20 \mathrm{~s}$ \\
$1 \mathrm{~Gb}$ & $0.18 \mu \mathrm{m}$ & $30-100 \mathrm{~nm}$ & $2-7 \mathrm{keV}$ & $\cong 950^{\circ} \mathrm{C} / 20 \mathrm{~s}$ \\
$4 \mathrm{~Gb}$ & $0.13 \mu \mathrm{m}$ & $20-80 \mathrm{~nm}$ & $1-5 \mathrm{keV}$ & $\cong 900^{\circ} \mathrm{C} / 10 \mathrm{~s}$ \\
$16 \mathrm{~Gb}$ & $0.10 \mu \mathrm{m}$ & $13-70 \mathrm{~nm}$ & $0.5-4 \mathrm{keV}$ & To be determined \\
$64 \mathrm{~Gb}$ & $70 \mathrm{~nm}$ & $10-60 \mathrm{~nm}$ & $0.3-3 \mathrm{keV}$ & To be determined \\
$256 \mathrm{~Gb}$ & $50 \mathrm{~nm}$ & $8-50 \mathrm{~nm}$ & $0.2-2 \mathrm{keV}$ & To be determined \\
\hline \hline
\end{tabular}

plantation and RTP from 0.5 to $0.1 \mu \mathrm{m}$ devices (Fig. 1) corresponding to boron high-dose implant energies spanning $10 \mathrm{keV}-200 \mathrm{eV}$, source drain junction depths from $0.2 \mu \mathrm{m}$ to $\cong 50 \mathrm{~nm}$, and device technologies spanning $16 \mathrm{Mb}$ to $\cong 16 \mathrm{~Gb}$ DRAM eras (see Table I).

\section{TEST STRUCTURES AND PROCESSING CONDITIONS}

Transmission electron microscopy (TEM) and secondary ion mass spectroscopy (SIMS) analysis arrays were fabricated on $200 \mathrm{~mm} p$-Si wafers. The wafers were first implanted with a $0.25 \mu \mathrm{m}$ technology $n$-well doping sequence $^{11,12}$ using a $9500 x \mathrm{R}$ implanter. A $0.25 \mu \mathrm{m}$ poly-Si layer was deposited over a $65 \AA \mathrm{SiO}_{2}$ film, implant doped with phosphorous, annealed, and plasma etched. The test arrays were then implanted with an $\mathrm{xR}$ (LEAP) tool with boron to a dose of $10^{15} \mathrm{~B} / \mathrm{cm}^{2}$ (Table II). The wafers were held at a tilt angle of $7^{\circ}$ (and $0^{\circ}$ twist) to allow for an analysis of beam shadowing effects.

The final ion energies spanned a range from $10 \mathrm{keV}$ to $200 \mathrm{eV}$. For ion energies of 5 and $2 \mathrm{keV}$, implants were done with drift (where the ion energy is determined by the extraction voltage at the ion source) and differential (where the final ion energy is determined by the difference between the extraction voltage and the reverse-polarity terminal supply) beams. For the differential mode beams, the source extraction voltage was $10 \mathrm{kV}$ for the $5 \mathrm{keV}$ case and $5 \mathrm{keV}$ for all other cases. The beam profile on the wafer for the differential mode beams was controlled by a focus electrode in the differential lens assembly. The focus voltage was held at $\cong 25 \mathrm{kV}$ for all differential mode beams. The vacuum conditions expected during high-dose implantation of complementary metal-oxide-semiconductor (CMOS) devices was simulated by loading four photoresist coated wafers onto the process wheel, in front of and after the test array wafer in the order of passage in front of the ion. The charge control plasma flood source (PFS) $)^{13}$ was operated with a constant flow of argon gas, establishing a wheel chamber pressure of $1.2 \times 10^{-5}$ mbar for all implants. The PFS was operated with an arc current of $6 \mathrm{~A}$ and guide tube voltage of $-10 \mathrm{~V}$ for all implants. The source gas was natural isotopic abundance $\mathrm{BF}_{3}$ and the automated tune time was less than $5 \mathrm{~min}$ for all implants.

The implanted wafers were annealed in a RTP Centura using a three-stage temperature ramp. Each wafer was preheated to $520{ }^{\circ} \mathrm{C}$ and then the closed-loop temperature was stabilized for $15 \mathrm{~s}$. The first temperature ramp was at $75^{\circ} \mathrm{C} / \mathrm{s}$ to a temperature $150^{\circ} \mathrm{C}$ lower than the target anneal temperature. The second ramp continued at $50{ }^{\circ} \mathrm{C} / \mathrm{s}$ to a temperature $100^{\circ} \mathrm{C}$ less than the final temperature. The last ramp was at $25^{\circ} \mathrm{C} / \mathrm{s}$ during the final $100{ }^{\circ} \mathrm{C}$ rise in wafer temperature. The soak temperatures in this study were 900,975 , and $1050{ }^{\circ} \mathrm{C}$. The anneal time at the highest temperature was 20 $\mathrm{s}$ and the gas ambient was flowing $\mathrm{N}_{2}$ at $5 \mathrm{slpm}$. The cool down rate was $\cong 35^{\circ} \mathrm{C} / \mathrm{s}$.

TABLE II. Implant conditions (xR LEAP: $a$ tool, ${ }^{a}$ June 1996).

\begin{tabular}{clccc}
\hline \hline Boron energy & Mode & Extraction & Beam current & Current density \\
\hline $10 \mathrm{keV}$ & Drift & $10 \mathrm{kV}$ & $8.9 \mathrm{~mA}$ & $0.5 \mathrm{~mA} / \mathrm{cm}^{2}$ \\
$5 \mathrm{keV}$ & Drift & $5 \mathrm{kV}$ & $4.5 \mathrm{~mA}$ & $0.15 \mathrm{~mA} / \mathrm{cm}^{2}$ \\
& Differential & $10 \mathrm{kV}$ & $8.0 \mathrm{~mA}$ & $0.09 \mathrm{~mA} / \mathrm{cm}^{2}$ \\
$2 \mathrm{keV}$ & Drift & $2 \mathrm{kV}$ & $1.0 \mathrm{~mA}$ & $0.02 \mathrm{~mA} / \mathrm{cm}^{2}$ \\
& Differential & $5 \mathrm{kV}$ & $4.0 \mathrm{~mA}$ & $0.14 \mathrm{~mA} / \mathrm{cm}^{2}$ \\
$1 \mathrm{keV}$ & Differential & $5 \mathrm{kV}$ & $2.0 \mathrm{~mA}$ & $0.10 \mathrm{~mA} / \mathrm{cm}^{2}$ \\
$500 \mathrm{eV}$ & Differential & $5 \mathrm{kV}$ & $1.5 \mathrm{~mA}$ & $0.05 \mathrm{~mA} / \mathrm{cm}^{2}$ \\
$200 \mathrm{eV}$ & Differential & $5 \mathrm{kV}$ & $0.8 \mathrm{~mA}$ & $0.02 \mathrm{~mA} / \mathrm{cm}^{2}$ \\
\hline \hline
\end{tabular}

${ }^{\mathrm{a} A}$ prototype tool was used for these implants; production specifications for the xR LEAP will reflect subsequent improvements in the machine performance. Implant dose was $10^{15} \mathrm{~B} / \mathrm{cm}^{2}$, current density measured from profiles at the full width at half maximum conditions. 


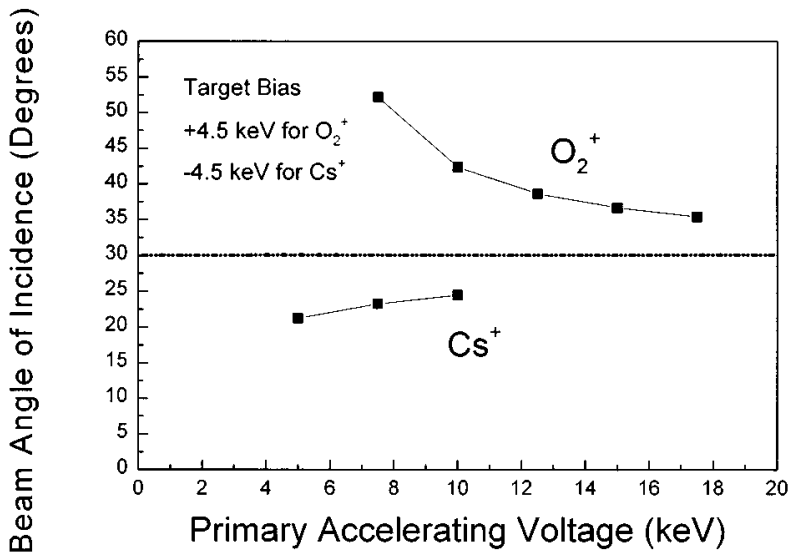

FIG. 2. Angle of incidence for $\mathrm{O}_{2}^{+}$and $\mathrm{Cs}^{+}$sputtering ions in the Cameca SIMS tool.

\section{ANALYSIS TOOLS AND CONDITIONS}

Cleaved cross-section slivers from the annealed wafers were polished to scanning electron micrograph sample quality on the front side by mechanical polishing with a tripod fixture using a "wedge" technique. ${ }^{14}$ After this first polish, the Boron doping layer was delineated by a variant on the "Catania cocktail" under UV illumination. ${ }^{15}$ This procedure of reactive etching the surface of a "bulk" material was developed by the Catania group to provide a sufficient source of hole carriers to facilitate the differential etching of the highly doped junction surface. The chemical etchant was $\mathrm{HF}(49 \%): \mathrm{HNO}_{3}(69.5 \%): \mathrm{CH}_{3} \mathrm{COOH}(100 \%)$ in a proportion of 1:3:8 (the Cantania recipe called for $\operatorname{HF}(40 \%)$ ). The UV illumination was provided by a $300 \mathrm{~W}$ UV lamp approximately $12 \mathrm{~cm}$ away from the sample and solution and an exposure time of $4 \mathrm{~s}$. The samples were then mechanically thinned on the second side to a thickness of $\cong 100 \mathrm{~nm}$. The samples where not ion milled after mechanical polishing. The TEM images were obtained using a Philips CM30 TEM operating at $300 \mathrm{kV}$. The samples were oriented along the $\mathrm{Si}\langle 011\rangle$ direction with a seven-beam collection setting of the objective lens aperture.

The SIMS profiles were obtained with $3 f$ and $4 f$ Cameca magnetic sector tools under a variety of operating conditions. Preliminary samples were taken with a Cameca $3 \mathrm{f}$ with 83 nA $\mathrm{O}_{2}{ }^{+}$beams with a $(200 \mu \mathrm{m})^{2}$ raster area and a $25 \mu \mathrm{m}$ diam analysis spot. Most of the samples were analyzed with a Cameca 4f with $330 \mathrm{nA} \mathrm{O}_{2}{ }^{+}$beams with a $(250 \mu \mathrm{m})^{2}$ raster area and a $30 \mu \mathrm{m}$ diam analysis spot. The sputter rate with the $3 \mathrm{f}$ tool was $1.8 \AA / \mathrm{s}$ and $5 \AA / \mathrm{s}$ with the $4 \mathrm{f}$ tool. The bombardment ions in both cases were $7.5 \mathrm{keV} \mathrm{O}_{2}{ }^{+}$with a sample bias of $+4.5 \mathrm{kV}$ (resulting in a net sputtering energy of $1.5 \mathrm{keV}$ per $\mathrm{O}$ atom). An oxygen leak was used with the samples analyzed with the $4 \mathrm{f}$ tool. The incidence angle of the sputtering beam was $52.24^{\circ}$ from the surface normal direction for a primary beam energy of $7.5 \mathrm{keV}$ with $+4.5 \mathrm{kV}$ sample bias (Fig. 2), which were the conditions used in this study.

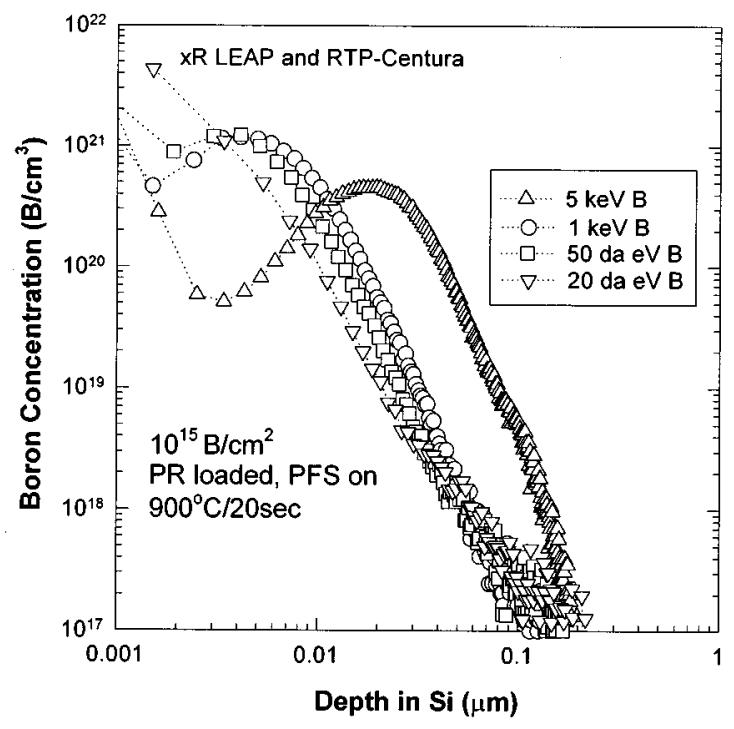

FIG. 3. Atomic profiles for annealed boron distributions for a RTP anneal at $900{ }^{\circ} \mathrm{C}$ for $20 \mathrm{~s}$ and energies ranging from $200 \mathrm{eV}$ to $5 \mathrm{keV}$ and a dose of $10^{15} \mathrm{~B} / \mathrm{cm}^{2}$.

\section{RESULTS}

\section{A. SIMS analysis}

SIMS profiles measured with an $\mathrm{O}_{2}$ bleed in the chamber resolved the peak concentrations of the annealed boron distributions at depths shallower than $0.01 \mu \mathrm{m}(<10 \mathrm{~nm})$ for energies as low as $500 \mathrm{eV}$ (Fig. 3). The surface equilibration effects during the first $3 \mathrm{~nm}$ of profiling without an $\mathrm{O}_{2}$ bleed is seen in the $5 \mathrm{keV}$ B profile. A trend that was noticed earlier ${ }^{16}$ is that the leading edges (at and below $\cong 10^{18} \mathrm{~B} / \mathrm{cm}^{3}$ ) of sub-keV profiles are often systematically deeper for lower-energy boron beams (Table III). This trend can be seen in the annealed profiles in Fig. 3 as well. As expected, the RTP soak temperature had a dramatic effect on the character of the annealed profiles (Fig. 4). For a soak temperature of $1050{ }^{\circ} \mathrm{C}$, the boron profiles at $\cong 10^{18} \mathrm{~B} / \mathrm{cm}^{3}$ had shifted $\cong 40 \mathrm{~nm}$ deeper than the profiles annealed at $900{ }^{\circ} \mathrm{C}$. At concentrations of $\cong 10^{19} \mathrm{~B} / \mathrm{cm}^{3}$, the shift is $\cong 60 \mathrm{~nm}$. The profiles annealed at $900{ }^{\circ} \mathrm{C}$ were similar in character to as-implanted profiles. ${ }^{16}$

\section{B. TEM analysis}

The TEM images of the etched junctions mirrored the effects seen in the SIMS profiles; with deeper delineated re-

TABLE III. Sheet resistance measurements of low-energy boron junctions.

\begin{tabular}{ccc}
\hline \hline Boron energy & Dose & Sheet resistance \\
\hline$(\mathrm{keV})$ & $\left(\right.$ ions $\left./ \mathrm{cm}^{2}\right)$ & $(\Omega /$ square $)$ \\
5 & $1.5 \times 10^{15}$ & 157.54 \\
5 & $8.0 \times 10^{14}$ & 317.01 \\
1 & $5.05 \times 10^{14}$ & 667.98 \\
0.5 & $12.0 \times 10^{14}$ & 2277.1 \\
\hline \hline
\end{tabular}

Anneal: $1000^{\circ} \mathrm{C}$ for $29 \mathrm{~s}$ in $\mathrm{N}_{2}$. Probe type-D (20 mil tip radius). 


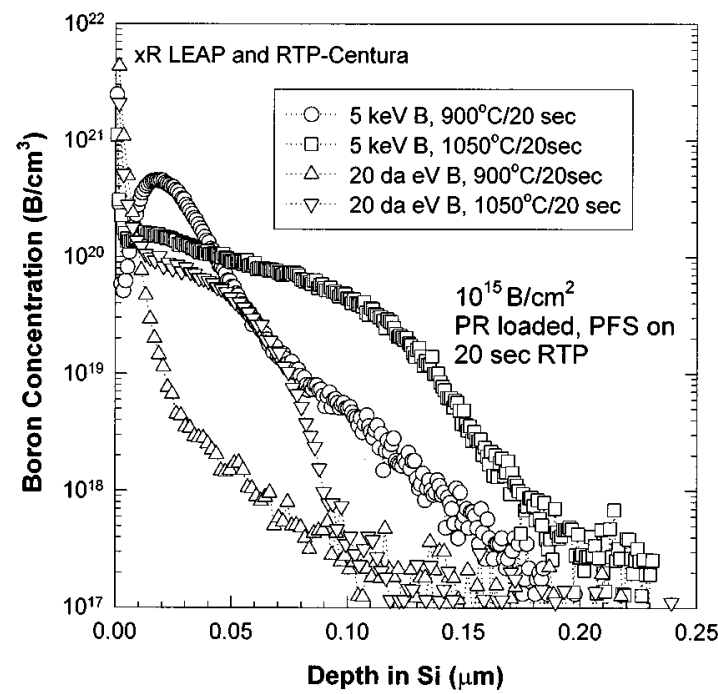

FIG. 4. Atomic profiles for annealed boron distributions annealed at 900 or $1050{ }^{\circ} \mathrm{C}$ for $20 \mathrm{~s}$ and energies $200 \mathrm{eV}$ or $5 \mathrm{keV}$. The ion dose was $10^{15} \mathrm{~B} / \mathrm{cm}^{2}$

gions imaged for the combinations of higher boron energies and higher anneal soak temperatures. The effect of boron energy for $900{ }^{\circ} \mathrm{C}$ annealed junctions is shown in Fig. 5. The delineation boundaries were somewhat rough (Fig. 6). The scale of the roughness ranged from $20 \%$ to $40 \%$ of the average depth of the delineated boundary, being higher for the shallower junctions. When TEM images of delineation etched samples were compared with SIMS profiles, the boron concentration at the boundary of the delineated regions far from the polyedges was $\cong 7 \times 10^{19} \mathrm{~B} / \mathrm{cm}^{3}$, for the samples etched for $4 \mathrm{~s}$ and $\cong 5 \times 10^{18} \mathrm{~B} / \mathrm{cm}^{3}$ for $8 \mathrm{~s}$ etch cycles. The TEM dopant delineation depth showed a consistent dependence on boron energy and soak temperature over the full range of this study (Fig. 7) Many of the TEM images showed enhanced etching of the heavily doped surface re- gions within $20-40 \mathrm{~nm}$ of the polygate edge. The lateral position of the enhanced etching was asymmetrical, reflecting the $7^{\circ}$ boron incidence angle used in this study. This effect was most pronounced for lower boron energies and soak temperatures (Fig. 8). No such features were seen in any of the cross-section TEM images where the dopant etch was not used.

\section{DISCUSSION}

This and other recent studies ${ }^{16,17}$ have seen that formation of shallow junctions with sub-keV boron implantation and RTP contains to the best of our knowledge, some new phenomena in addition to the known effects of enhanced dopant diffusion and defect interactions. ${ }^{2}$ The principal effects seen in this study are the deeper tails of the lower-energy boron profiles, both as-implanted ${ }^{16}$ and annealed.

The deeper boron tails for lower-energy, sub-keV beams are highly suggestive of a combination of channeling and damage accumulation effects. Molecular dynamic (MD) calculations ${ }^{18}$ showed that boron channeling along $\mathrm{Si}\langle 110\rangle$ directions is a significant effect for beam energies as low as $50 \mathrm{eV}$. The lower damage deposition of lower-energy beams means that a higher fraction of the boron dose is implanted before sufficient lattice damage is accumulated to begin to shut down the $\mathrm{Si}\langle 110\rangle$ channeling paths, resulting in a higher fraction of deeply penetrating boron. In addition to these considerations, recent MD studies ${ }^{19}$ have indicated that thermal effects may also contribute to enhanced boron migration during the implant for boron implants in the $20-500 \mathrm{eV}$ range. Because the sub-keV implants were all done with the same source extraction energy, ion neutralization effects, which were seen in previous studies with large differences between the extraction and final energies, from 60 to $10 \mathrm{keV}$ for example, ${ }^{20}$ are not considered to be significant here. The understanding of this effect will wait on further studies of the effects of wafer temperature, beam current, and predamage
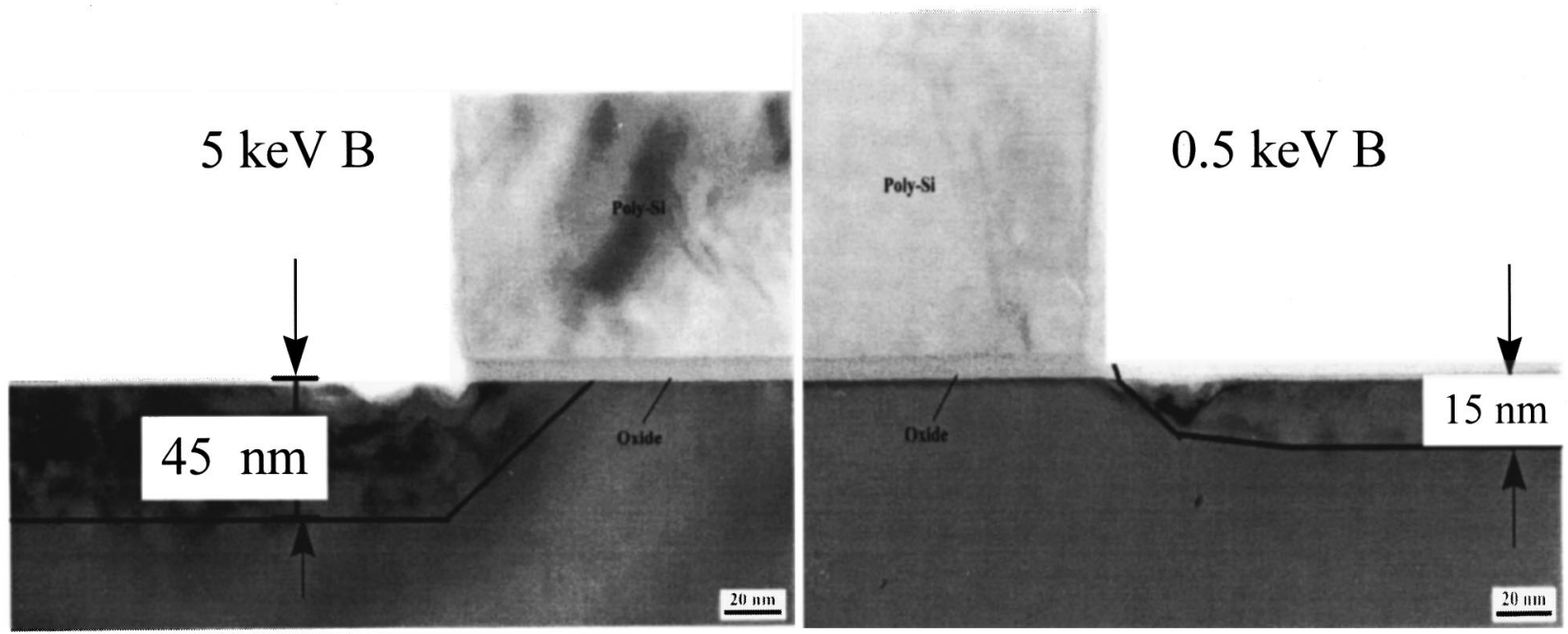

Fig. 5. Cross-section TEM of selectively etched boron junctions for 5 and $0.5 \mathrm{keV}$ boron implant at a dose of $10^{15} \mathrm{~B} / \mathrm{cm}^{2}$ and a RTP anneal at $900{ }^{\circ} \mathrm{C}$ for 20 s. Note the etched surface "notches" near the poly-Si mask. The oxide thickness is $65 \AA$ A. The etch delineation boundaries are drawn as an aid to the eye. 


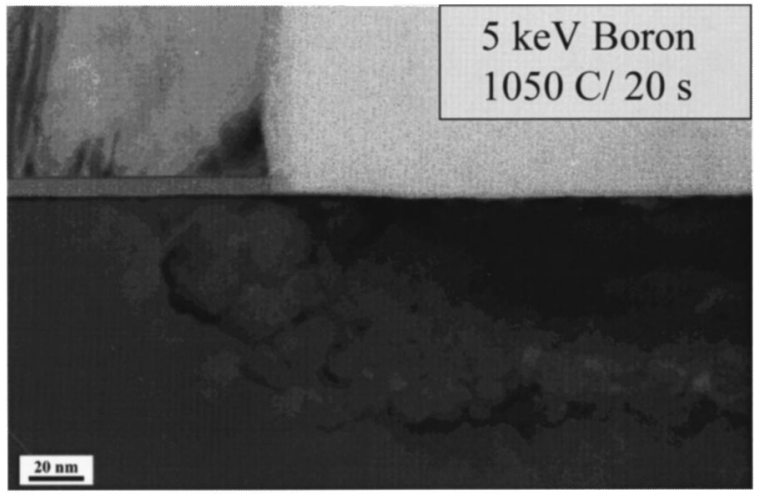

FIG. 6. TEM image of selectively etched boron junction after implantation at $5 \mathrm{keV}$ and anneal at $1050^{\circ} \mathrm{C}$ for $20 \mathrm{~s}$. Note the wavy interface between etched and unetched regions.

conditions on as-implanted and annealed profiles as well as new insights resulting from atomic-scale modeling of the behavior of sub-keV beams in $\mathrm{Si}^{21}$

The location of dopants and defects near the edge of the source/drain have a profound effect on the performance of deep submicron transistors. ${ }^{22}$ In this study, the beam incidence angle was set at $7^{\circ}$ to allow an analysis of junction asymmetry coupled to Monte Carlo models of lateral straggling $^{23}$ (to be reported later along with a study of beam divergence effects). The dramatic enhanced etching seen in the shallowest junctions near the edge of the polygate (Figs. 5,8 , and 10) is an indication of a significant lateral dopant level variation near the polymask. Since no distortion of the $\mathrm{Si}$ surface was seen in samples that were not dopant etched, edge effects from the plasma etching of the polygates structures are not important here. Since the locations of the enhanced etching regions were offset on either side of the polygates in a manner consistent with the $7^{\circ}$ beam incidence angle, possible strain effects during RTP annealing or defects

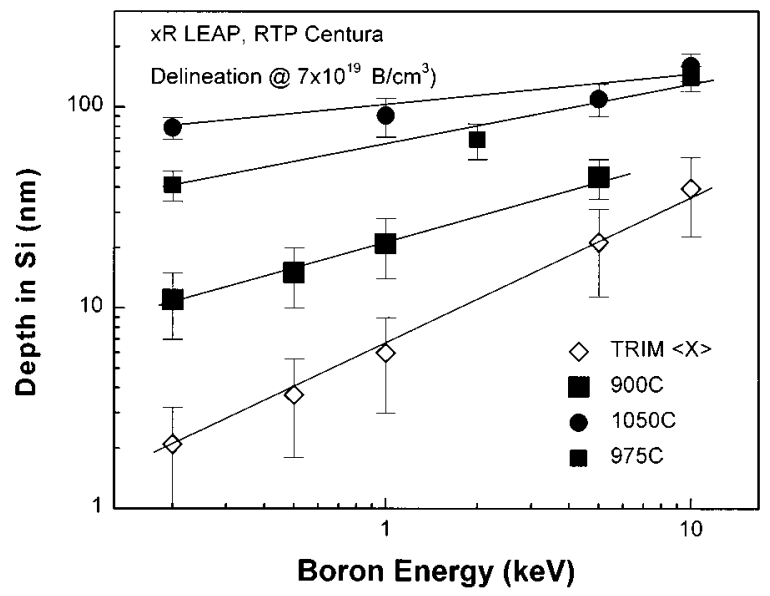

FIG. 7. Variation with ion energy and anneal temperature of the vertical depth of the delineation boundary after selective etching of the boron junctions. The error bars on the delineation depth are the observed roughness of the interface. Also shown is the mean range and straggling (error bars) for B range in $\mathrm{Si}$ calculated with the TRIM MC code.
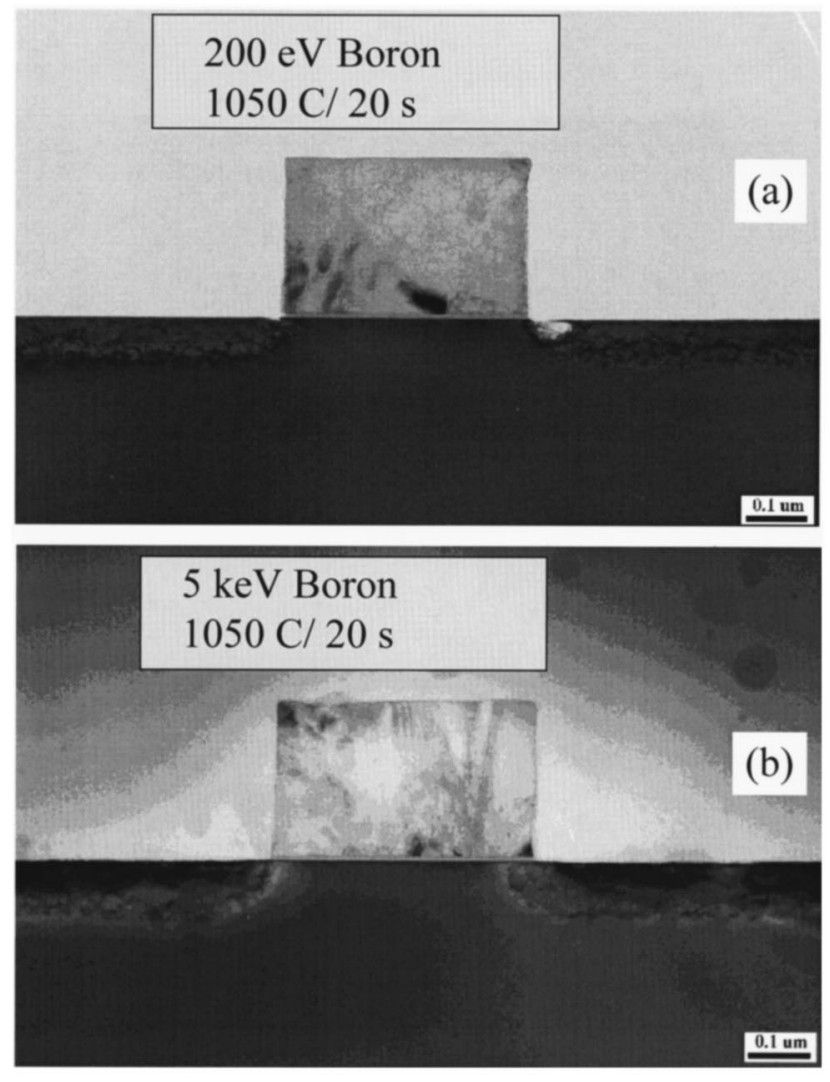

FIG. 8. TEM images of etched boron junction after implantation with (a) 200 $\mathrm{eV}$ or (b) $5 \mathrm{keV}$ boron and an anneal at $1050{ }^{\circ} \mathrm{C}$ for $20 \mathrm{~s}$. Note that the enhanced etching feature near the edge of the poly-Si mask is seen only in the lower-energy implant. For the $5 \mathrm{keV}$ implant the junction asymmetry for this $7^{\circ}$ incidence angle beam is easily seen.

associated with different amorphous-to-crystal regrowth rates along various crystal directions, which would be expected to be symmetric with respect to the polymask, are also not considered to be the cause of the observed enhanced etching.

Lateral doping variations are expected to arise near the edges of masks due to the "extra" dopant arriving at the $\mathrm{Si}$ surface in the form of ions that entered the top and sides of the polygate and emerged through a combination of reflection and lateral straggling to the polysidewall. ${ }^{24}$ Preliminary modeling of the positions of "extra" doping regions for 1 $\mathrm{keV} \mathrm{B}$ ions are in qualitative agreement with the observed enhanced etching. 25

\section{SUMMARY}

The challenges of the exponential scaling of CMOS source/drain junctions to shallower depths (Fig. 1) was reflected in the listing of "low-energy, high-current boron (implanters)" and "low-leakage shallow junctions" as priority needs for doping technology in the 1994 SIA Technology Roadmap. ${ }^{1}$ The challenges of obtaining adequate beam currents of low-energy boron ions with conventional beamline technology drove the exploration of techniques such as plasma immersion ion implantation (PIII), which operate 


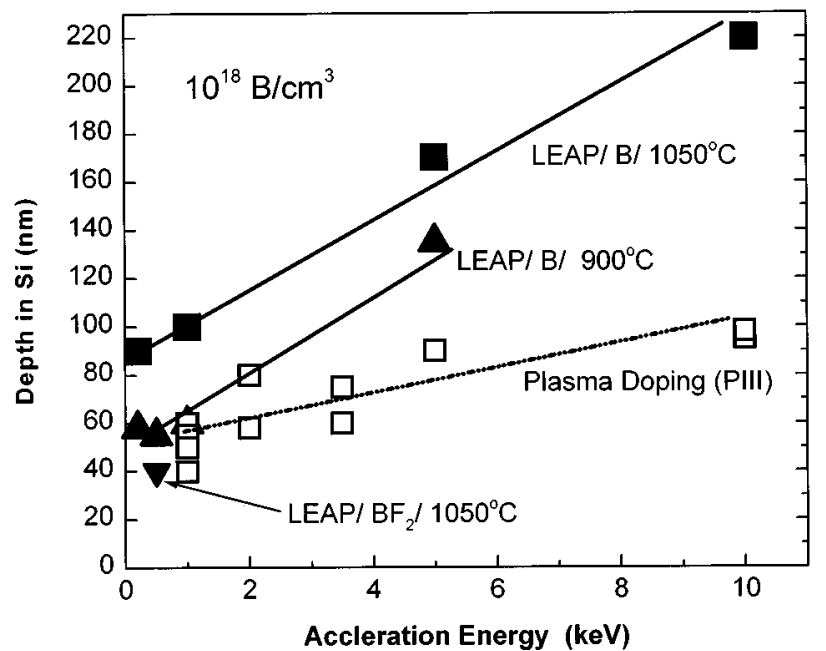

FIG. 9. Variation of the depth of boron concentration at $10^{18} \mathrm{~B} / \mathrm{cm}^{3}$ for this study and recent results with plasma immersion ion implantation (PIII) techniques (Ref. 26). The ion dose in this study was $10^{15} \mathrm{~B} / \mathrm{cm}^{2}$. Annealed junctions are compared in both cases.

very efficiently in the the $1-10 \mathrm{keV}$ energy range. ${ }^{26}$ Advances in beamline technology and rapid thermal processing have resulted in fabrication of highly doped boron junctions at depths of 40-60 nm, comparable to the best reported results from PIII techniques (Fig. 9) ${ }^{26}$ Although much work remains to be done, these results demonstrate that the basic structural requirements, $\cong 50 \mathrm{~nm}$ boron junction depths, with most of the dopant profile within $\cong 20 \mathrm{~nm}$ of the surface, around a $0.1 \mu \mathrm{m}$ wide gate stack (Fig. 10), equivalent to 4-16 Gb DRAM technology can be fabricated with existing production implant and RTP techniques.

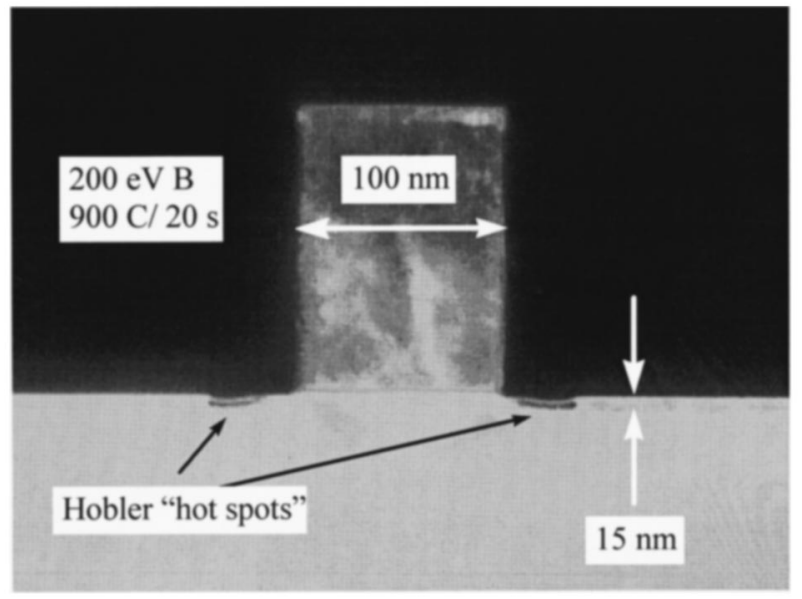

FIG. 10. Cross-section TEM image of a selectively etched B junction after an implant at $200 \mathrm{eV}$ and an anneal at $900{ }^{\circ} \mathrm{C}$ for $20 \mathrm{~s}$. The gate mask width is $100 \mathrm{~nm}$ and the delineation depth for the boron dopants was $\cong 15 \mathrm{~nm}$. Note the enhanced etching on either side of the polymask. The asymmetry is a result of the $7^{\circ}$ angle on incidence of the B beam in this study.

\section{ACKNOWLEDGMENTS}

The authors thank the many contributors to this study, in particular; P. Maillot and K. Bryant of SEMATECH for providing the TEM/SIMS test arrays, K. Carpentier of IBM/ ASTC for assisting in getting $200 \mathrm{~mm}$ prime wafers and the ongoing valuable discussions with D. Armour of Salford, G. Holber at Lucent Technologies, T. Dias de la Rubia at Lawrence Livermore Laboratory, L. A. Larson at SEMATECH and S. Prussin at UCLA. The meticulous and enthusiastic support of the Applied Materials Applications Laboratory personnel, in particular, W. Boyd, M. Castle, and A. Murrell, were key to the success of this work.

${ }^{1}$ The National Technology Roadmap for Semiconductors (Semiconductor Industry Association, San Jose, CA, 1994).

${ }^{2}$ E. Chason, S. T. Picrauz, J. M. Poate, M. I. Current, J. O. Borland, T. Diaz dela Rubia, D. J. Eaglesham, W. O. Holland, M. E. Law, C. W. Magee, J. W. Mayer, J. Melngailis, and A. F. Tasch, Mater. Res. Soc. Symp. Proc. 396, 859 (1996).

${ }^{3}$ J. G. England, L. Joyce, C. Burgess, S. Moffatt, M. A. Foad, D. Armour, and M. I. Current, in Ion Implantation Technology-96, edited by E. Ishida, T. C. Smith, M. I. Current, S. Mehta, S. Banerjee, A. Tasch, and L. A. Larson, IEEE No. 96 TH8182 (1997), pp. 470-473.

${ }^{4}$ T. J. Riley, A. K. Nanda, G. Miner, M. F. Pas, S. Hossain-Pas, and L. A. Velo, Mater. Res. Soc. Symp. Proc. 429, 15 (1996).

${ }^{5}$ A. K. Nanda, T. J. Riley, G. Miner, M. F. Pas, and S. Hossain-Pas, Mater. Res. Soc. Symp. Proc. 429, 23 (1996).

${ }^{6}$ M. F. Pas, C. R. Cleavelin, S. D. Pas, J. Kuehne, J. Kittl, R. Wise, S. Hsia, and P. Hey, in Rapid Thermal Processing '96, edited by R. B. Fair, M. L. Green, B. Lojek, and R. P. S. Thakur (Boise, Idaho), pp. 21-27. ${ }^{7}$ B. El-Kareh, J. Vac. Sci. Technol. B 12, 172 (1994).

${ }^{8}$ G. D. Hutcheson and J. D. Hutcheson, Sci. Am. (Int. Ed.) 275, 54 (1996). ${ }^{9}$ C. A. Warwick and A. Ourmazd, IEEE Trans. Semicond. Manuf. 6, 284 (1993).

${ }^{10}$ M. I. Current, Semiconductor Silicon-98 (Electrochemical Society, 1998) (to be published).

${ }^{11}$ A. Horie, H. Nakaoka, H. Umimoto, K. Yamashita, M. Takase, N. Shimizu, B. Mizuno, and S. Odanaka, Tech. Dig. Int. Electron Devices Meet. 94, 485 (1994).

${ }^{12}$ M. I. Current, M. Castle, V. Chia, G. Mount, S. Weinzierl, S. Prussin, and L. A. Larson, in Ion Implantation Technology-96, edited by E. Ishida, T. C. Smith, M. I. Current, S. Mehta, S. Banerjee, A. Tasch, and L. A. Larson, IEEE No. 96 TH8182 (1997), pp. 194-197.

${ }^{13}$ H. Ito, M. I. Current, in Ion Implantation Technology-96, edited by E. Ishida, T. C. Smith, M. I. Current, S. Mehta, S. Banerjee, A. Tasch, and L. A. Larson, IEEE No. 96TH8182 (1997), pp. 432-435.

${ }^{14}$ S. J. Klepeis et al., Mater. Res. Soc. Symp. Proc. 117, 179 (1988).

${ }^{15}$ C. Spinella, V. Raineri, F. La Via, and S. U. Campisano, J. Vac. Sci. Technol. B 14, 179 (1996).

${ }^{16}$ M. A. Foad, J. G. England, S. Moffatt, and D. G. Armour, in Ion Implantation Technology-96, edited by E. Ishida, T. C. Smith, M. I. Current, S. Mehta, S. Banerjee, A. Tasch, and L. A. Larson, IEEE No. 96 TH8182 (1997), pp. 603-606.

${ }^{17}$ N. Hatzopoulos, S. Suder, J. A. van den Berg, S. E. Donnelly, C. E. A. Cook, D. G. Armour, M. Lucassen, L. Frey, P. Bailey, C. T. Noakes, D. Panknnin, W. Fukarek, M. A. Foad, J. G. England, S. Moffatt, and H. Ohno, in Ion Implantation Technology-96, edited by E. Ishida, T. C. Smith, M. I. Current, S. Mehta, S. Banerjee, A. Tasch, and L. A. Larson, IEEE \#96TH8182 (1997) 527-530.

${ }^{18}$ R. Smith and R. P. Webb, Philos. Mag. Lett. 64, 253 (1991).

${ }^{19} \mathrm{~T}$. Diaz de la Rubia (private communication).

${ }^{20}$ D. F. Downey, R. J. Eddy, and S. Mehta, Nucl. Instrum. Methods Phys. Res. B 74, 160 (1993).

${ }^{21}$ M.-J. Caturla and T. Diaz de la Rubia, Mater. Res. Soc. Symp. Proc. 438, 89 (1997)

${ }^{22}$ M. Duane, P. Nunan, M. ter Beek, and R. Subramanian, J. Vac. Sci. Technol. B 14, 218 (1996). 
${ }^{23}$ S. T. Nakagawa, L. Thome, H. Saito, and C. Clerc, Nucl. Instrum. Methods Phys. Res. B 121, 36 (1997).

${ }^{24}$ G. Hobler and S. Selberherr, IEEE Trans. Comput.-Aided Des. 8, 450 (1989).
${ }^{25} \mathrm{G}$. Hobler (private communication).

${ }^{26}$ M. I. Current, N. W. Cheung, P. L. F. Hemment, I. Yamada, and J. Matsuo, in Ion Implantation Science and Technology, edited by J. F. Ziegler (Ion Implantation Technology, 1996), pp. 92-174. 